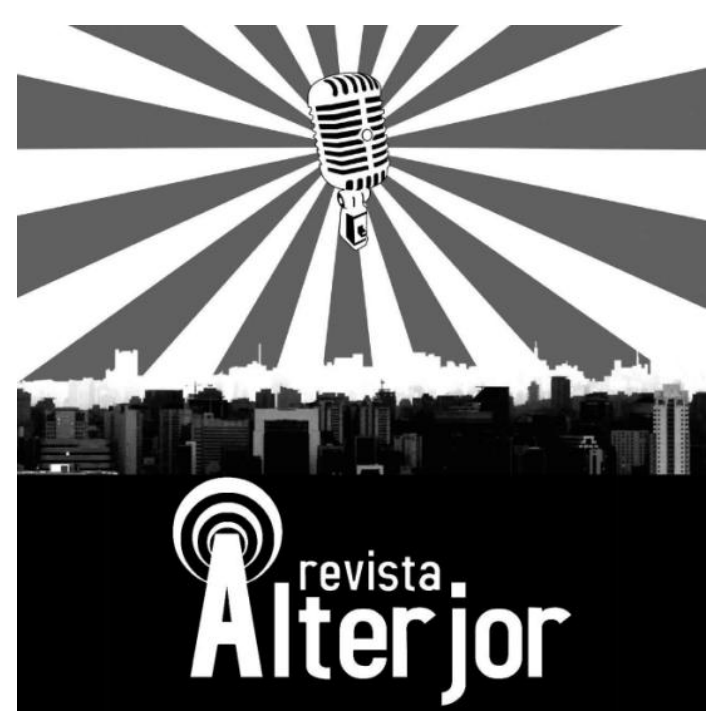

\title{
O ARQUIVAMENTO E A DISPONIBILIZAÇÃO DO DOCUMENTÁRIO AUDIOVISUAL UNIVERSITÁRIO: FORMAS DE CONSUMO E APRENDIZADO
}

\author{
Paulo Eduardo Silva Lins Cajazeira ${ }^{1}$
}

RESUMO: Busca-se compreender como os processos de aprendizado estão para além das etapas de produção e pós-produção documentária audiovisual universitária. Dessa forma, identifica-se como o arquivamento, disponibilização e consumo estão presentes nesse processo e diálogo com os ambientes digitais de informação. Uma vez que esses lugares funcionam enquanto ambientes memorialísticos para a salvaguarda e consumo audiovisual.

PALAVRAS-CHAVE: Documentário. Arquivo audiovisual. Ambientes digitais. Práticas de arquivamento. Consumo online.

ABSTRACT: We seek to understand how the learning processes are beyond the stages of production and post-production university audiovisual documentary. Thus, it is identified how archiving, availability and consumption are present in this process and dialogue with digital information environments. Since these places function as memorialistic environments for the safeguarding and audiovisual consumption.

KEYWORDS: Documentary. Audiovisual archive. Digital environment. Archiving practices. Online consuption.

\footnotetext{
${ }^{1}$ Professor Associado na Universidade Federal do Cariri (UFCA); Docente permanente no Programa de Pós-Graduação em Biblioteconomia e no Curso de Jornalismo (UFCA); Pós-Doutor em Ciências da Comunicação pela Universidade da Beira Interior (Portugal); Doutor em Comunicação e Semiótica (PUC-SP); Mestre me Comunicação e Linguagens (UTP-PR) e Bacharel em Comunicação Social Jornalismo (PUC-PR). E-mail: paulo.cajazeira@ufca.edu.br
}

Revista ALTERJOR

Grupo de Estudos Alterjor:Jornalismo Popular e Alternativo (ECA-USP)

Ano 10 Volume 02 Edição $22 \quad$ Juho-Dezembro de 2020

Avenida Professor Lúcio Martins Rodriģues, 443, Cidade Universitária, São Paulo, CEP: 05508-020 


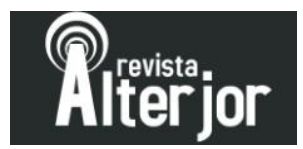

\section{Reflexões Introdutórias}

Da produção a disponibilização dos documentários audiovisuais tem-se uma grande caminhada. Os processos de experiência são vastos, múltiplos e repletos de aprendizados que vão desde a escolha da temática abordada, as etapas de pré-produção, entrevistas, captação das imagens e pós-produção, para finalizar a edição visando a sua exibição como produto de um registro. Essas etapas e procedimentos podem ser vislumbrados nas universidades, a partir dos cursos de Jornalismo no Brasil, a exemplo do Curso de Jornalismo da Universidade Federal do Cariri, um dos 39 cursos de jornalismo em universidades federais brasileiras. Uma vez que se tem nas disciplinas vinculadas ao telejornalismo, o contato com a linguagem e formato audiovisual: o documentário.

Além do processo de produção é pertinente e necessário discutir sobre o arquivamento e a disponibilização desses documentários. Uma vez que, são esses estágios que impulsionam a circulação dos produtos, a troca de informações e conhecimentos e o acesso, uso e recuperação da informação - sobretudo em ambientes digitais. Dessa forma, sendo possível observar e identificar as transmutações do desenvolvimento com o documentário no ambiente universitário.

A visualização descrita acima é identificada a partir das experiências laboratoriais do curso de Jornalismo da Universidade Federal do Cariri (UFCA), que está situada na região sul do Estado do Ceará, nordeste do Brasil. Na qual a problemática acerca do tema de pesquisa proposto, proporciona uma reflexão a ser discutida a nível teórico-pragmático, gerando resultados para serem aplicados no cotidiano desses ambientes informacionais audiovisuais. Assim, é possível levantar o seguinte questionamento: Como as práticas de arquivamento e disponibilização on-line do produto audiovisual jornalístico desenvolvem novas formas de consumo e aprendizado no ambiente universitário?

Aponta-se como objetivo geral do estudo compreender como ocorrem as práticas de arquivamento e disponibilização dos documentários audiovisuais nas plataformas online. Em relação aos objetos específicos: a) mapear as plataformas on-line de 


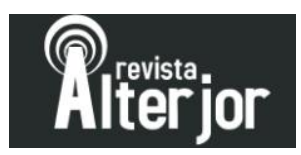

disponibilização e; b) refletir sobre os novos formas de consumo audiovisual a partir dos avanços tecnológicos.

A pesquisa sobre os documentários, vistos sob o âmbito dos arquivos audiovisuais direciona a pesquisa para a interdisciplinaridade de três campos do conhecimento: Biblioteconomia, Ciência da Informação (BCI) e o Jornalismo. Essas três áreas lidam de formas diferentes com o objeto de estudo. Enquanto as duas primeiras se situam no processo de organização e representação da informação; a terceira é responsável pela produção dessas imagens em movimento (o audiovisual).

\section{A linguagem audiovisual e o processo de hibridação}

A linguagem audiovisual é marcada pela hibridação do uso de dois elementos: imagem e áudio. A partir de um sistema combinatório, esses dois elementos interagem entre si e desenvolvem uma nova possibilidade de linguagem: a imagem em movimento ou, como tem sido denominado na pesquisa, audiovisual. O uso do termo audiovisual é utilizado sob o fundamental de que nele encontra-se não apenas a imagem em movimento, mas o elemento áudio como parte fundamental de sua base conceitual. Assim, diferentemente do termo imagem em movimento, no qual não se tem uma obrigatoriedade desse elemento.

Nesse processo de reflexão é costumeiro relacionar o surgimento do audiovisual com o desenvolvimento da história do cinema, enquanto uma das primeiras linguagens que experimentaram essa nova possibilidade de trazer movimento a imagem. Porém, de acordo com Alves, Fontoura e Antoniutti (2008) pode-se identificar indícios dessa linguagem com o teatro de sombras da China milenar, como uma das primeiras visualizações de trabalho original com a imagem em movimento. Nesse processo, eram utilizadas as projeções de figuras humanas, animais ou objetos, que manipuladas atrás de uma tela branca e iluminada, eram movimentadas pelos artistas e causavam a sensação das imagens estarem se movimentando.

Assim, é partir dessa primeira experimentação no Oriente, que se vislumbra o desenvolvimento de novos suportes e técnicas, de fato, para a criação da imagem em 


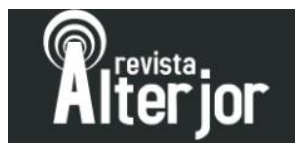

movimento de forma mais refinada e tecnológica. Esse fato é identificado no século $\mathrm{XV}$, com o desenvolvimento da câmera escura ${ }^{2}$ - o primeiro aparelho para projetar imagens na história ocidental -, que trouxe mudanças significativas para a sociedade. A invenção da câmara escura é atribuída a dois grandes inventores, Leonardo da Vinci e o físico napolitano Giambattista Della Porta, que aprimorou o invento no século XVI (Alves; Fontoura; Antoniutti, 2008). Já no século XVII, o princípio inverso da câmara escura foi utilizado para criar a lanterna mágica ${ }^{3}$. Demonstrando o processo de evolução, quando se busca demonstrar o desenvolvimento das práticas audiovisuais ao longo da história.

Com a criação dessas invenções, a linguagem fotográfica foi se apropriando e novos dispositivos foram sendo desenvolvidos: fenacistocópio (Joseph-Antoine Plateau, 1832); praxinoscópio (Émile Reynaud, 1877), fuzil fotográfico (Étienne-Jules Marey, 1878); cronofotografia (Étienne-Jules Marey, 1878); cinetoscópio (Thomas Edison, 1891) e o cinematógrafo (Auguste e Louis Lumière, 1895), até que os estudos e pesquisas de Louis-Jacques Daguerre e Joseph Nicéphore Niepce conseguiram desenvolver técnicas para conseguir imagens em movimento (Alves; Fontoura; Antoniutti, 2008).

Mas, como exposto anteriormente, foi com o surgimento do cinema e, principalmente, com as ideias dos irmãos Auguste e Louis Lumière que a linguagem audiovisual adquire um significado mais amplo e histórico - o que pode ser definido como um marco do audiovisual. Eles aperfeiçoaram o objeto desenvolvido por Thomas Edison e desenvolveram o cinematógrafo no século XIX. Assim, se através da grande tela do cinema o audiovisual produziu uma grande revolução da imagem, que já não era estática, com o avanço tecnológico e a chegada da televisão, mais uma vez, era observado uma transformação nos processos e experimentações audiovisuais.

\footnotetext{
${ }^{2}$ Conforme explicam Alves, Fontoura e Antoniutti (2008, p. 34) "a câmera escura consistia em uma caixa fechada, com um pequeno orifício coberto por uma lente, na qual penetravam e se cruzavam raios refletidos pelos objetos exteriores, projetando a imagem invertida no fundo da caixa".

${ }^{3}$ Uma nova caixa de forma cilíndrica, que era iluminada a vela e projetava as imagens a partir de uma lâmina de vidro (ALVES; FONTOURA; ANTONIUTTI, 2008).
} 


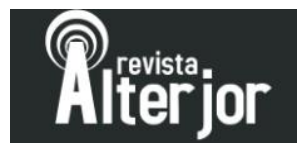

A linguagem adaptada do cinema foi sendo aprimorada para uma tela menor e mais onipresente no cotidiano das pessoas, pois ela estaria presente nos lares, todos os dias e todas as horas. Uma enxurrada de conteúdos e produtos audiovisuais, que começava a ser produzido em diferentes formas e formatos e disponíveis a um clique do controle do remoto. Nascia, assim, um fenômeno comunicacional barato, acessível e colocando o audiovisual como uma grande linguagem visual e sonora.

Essa imagem que está no imaginário da sociedade sofreu uma nova alteração com a introdução da internet, na qual foi instaurado um novo processo de audiovisualidade $^{4}$ (Rossini; Silva, 2009), que foi iniciado com o cinema e a televisão. Assim, essa audiovisualidade estaria presente nos meios de comunicação tradicionais e na sua relação com as novas mídias (como a internet), estando ao alcance da população dentro dos seus lares em outros espaços através da mobilidade dos dispositivos (Souza; Cajazeira, 2016).

\section{A criação dos arquivos}

Ao se referir sobre a origem do arquivo Vieira (2016), explica que ela parte da necessidade do homem em registrar o seu cotidiano e como evidencia Leopoldo Sandri (1968 apud Cruz Mundet, 2012: p. 21, tradução nossa), “[...] a história dos arquivos está estreitamente ligada a história da escrita e, mais precisamente, a história da difusão e do uso da mesma, portanto, do material escrito". Esse material escrito funciona como prova, como uma lembrança visível do que já foi vivido pelo homem ao longo da vida.

Já o arquivo moderno como esse lugar físico está relacionado com a Revolução Francesa, como forma de rastreamento do conhecimento social e de documentos históricos (Ricoeur, 2007). Assim, para Foucault (2009), os arquivos representam práticas discursivas fazendo com que as declarações possam emergir como eventos, sendo usadas ou ignoradas como coisas ou objetos que resguardam informações e transformando-se em conhecimento e memória da humanidade.

\footnotetext{
${ }^{4}$ Esse conceito parte da percepção na qual as novas mídias e a convergência entre elas, propicia o surgimento de uma linguagem audiovisual diferenciada. A partir da experimentação e exploração, sobretudo, da internet e suas características próprias de produção audiovisual.
} 


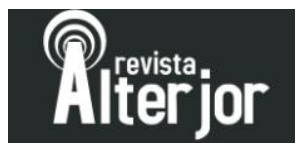

Se o arquivo está relacionado com a escrita isso implica dizer, de certa forma no passado, apenas existiam arquivos escritos. Essa mesma visão sobre os arquivos audiovisuais pode ser vista no Manual de Arranjo e Descrição de Arquivos, publicado pela Associação de Arquivistas Holandeses, em 1898. No manual, o termo "arquivo" é definido como um:

Conjunto de documentos escritos, desenhos e material impresso, recebidos ou produzidos oficialmente por determinado órgão administrativo ou por um de seus funcionários, na medida em que tais documentos se destinavam a permanecer na custódia desse órgão ou funcionário (Associação dos arquivistas holandeses, 1973: p. 13).

A partir dessas duas visões apresentadas, percebe-se que o arquivo esteve relacionado, por muito tempo, com a escrita. Porém, é preciso destacar que esse modelo de arquivo perpassou a história durante muitos anos, dentro de um contexto histórico. Mas, passível de transformações e complementações com o surgimento de outros tipos de materiais como, por exemplo, as fotografias, arquivos sonoros e audiovisuais - que podem ser visualizados na atualidade. Assim, em uma nota na edição traduzida e publicada no Brasil pelo Arquivo Nacional encontra-se essa observação: "a definição foi redigida há muitos anos, antes de generalizadas as reproduções fotográficas, ou outras. Se escrita hoje, nela seriam, sem dúvida, incluídas” (Associação dos arquivistas holandeses, 1973: p. 14).

Essa observação realizada no manual é uma importante mudança para a compreensão da expansão e agregação de outros tipos de arquivos, bem como uma conscientização latente sobre os outros modelos documentais. Essa ressalva é feita pela Escola dos Annales em 1929, ampliando a concepção de documento, para além do texto, como fonte histórica. Dessa forma, "há que tomar a palavra 'documento' no sentido mais amplo, documento escrito, ilustrado, transmitido pelo som, a imagem, ou de qualquer outra maneira" (Samaran, 1961: p. 12 apud LE GOFF, 2003: p. 540). O que revela uma importância mudança de pensamento acerca de outras linguagens, que se relacionam com a produção de arquivos audiovisuais na sociedade. 


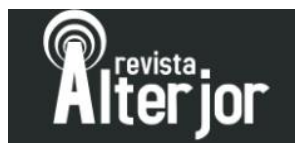

A temática do arquivo também é discutida por Ray Edmondson (1998; 2017), que na visão do autor se aproxima com a sensação do que a palavra arquivo proporciona aos sujeitos a sensação de um lugar velho, abandonado, repleto de caixas ou pastas contendo papéis (documentos). Ele é visto como uma espécie de arquivo "morto", no qual encontra-se uma pessoa mais velha trabalhando em um local solitário e abandonado. Esse poderia compreendido enquanto um cenário apresentado pela visão sobre o arquivo visto enquanto instituição, sob o ângulo do estereótipo cunhado pela sociedade. Nessa visão apresentada, o arquivo é resumido a uma função de salvaguarda com pouca utilidade, apenas enquanto estoque.

Na compreensão sobre o que seria um documento tem-se a contribuição dos estudos de Buckland (1997), que no artigo intitulado "What is a document?" traz uma discussão sobre o conceito atrelado ao campo da Documentação. De acordo com o autor a palavra documento denota a informação como coisa (Buckland, 1991). o interesse em compreender o conceito de documento, sobretudo no campo da ciência da informação, em razão dos sistemas de armazenamento e recuperação da informação (o registro).

Inicialmente, o documento esteve vinculado a informação textual. a mudança de concepção surge com o interesse na multimídia, uma vez que os fenômenos podem ser vistos a partir de eventos, processos, imagens e objetos, além do texto (Buckland, 1997). Essa percepção trazida pelo autor dialoga com a proposta da dissertação em compreender os arquivos e documentos audiovisuais.

Assim, o trabalho desenvolvido por Paul Otlet e Suzanne Briet como explicita Buckland (1997), foi fundamental para uma abertura sobre as formas físicas de informação. Assim, tais documentos de acordo com Otlet (1934) no Tratado de Documentação, podem configurar como os objetos naturais, artefatos, objetos com vestígios de atividade humana (como descobertas arqueológicas), modelos explicativos, jogos educativos e obras de arte.

Com isso, enquanto o arquivo se apresenta como um lugar (instituição), o objeto identificado e encontrado nesse arquivo é o documento, que pode ser de caráter físico ou digital. $\mathrm{O}$ arquivo tem a potencialidade não somente em realizar a salvaguarda, mas, 


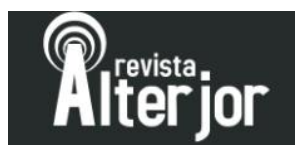

também, de organizar e representar, primeiramente, esses documentos através de uma sistematização. Essa sistematização é feita por um profissional qualificado e habilitado (arquivista ou bibliotecário, por exemplo). Esse documento pode assumir diferentes formatos como o audiovisual, sonoro ou iconográfico - podendo ser encontrado em sua forma física ou digital.

\section{Trabalho de Conclusão de Curso: o produto audiovisual jornalístico}

O Trabalho de Conclusão de Curso (TCC) é uma disciplina obrigatória na matriz curricular na maioria dos cursos de graduação no Brasil. No TCC o discente desenvolve uma reflexão teórica ou teórico-prática - dependendo do curso e instituição - a partir do seu conhecimento adquirido ao longo dos semestres de disciplinas teóricas e práticas, discussões e aprendizado em sala de aula junto aos professores e colegas de turma. No Projeto Pedagógico do Curso de Jornalismo (2016), a disciplina de TCC ocorre no oitavo semestre, com carga horário de 320 horas. Tal disciplina é precedida por outra, Pesquisa em Comunicação no sétimo semestre, em que o discente direciona a sua pesquisa e o seu modelo de TCC com o apoio do professor que ministra a disciplina.

As modalidades do TCC podem variar de instituição para instituição e de curso para curso. Especificamente no curso de Jornalismo da Universidade Federal do Cariri (UFCA), encontram-se duas opções: a monografia e o produto jornalístico. A escolha por uma dessas duas possibilidades deve ocorrer no semestre anterior. Assim, o discente tem um ano para o desenvolvimento até o momento da defesa do seu TCC, como componente para o término da graduação em Jornalismo.

De acordo com o Projeto Pedagógico (2016: p. 129) o

[...] Produto Jornalístico permite que o (a) aluno (a) desenvolva, de forma experimental, a criação de um produto jornalístico que possa contribuir para o amadurecimento profissional. A disciplina está relacionada ao campo da experimentação, mas exige rigor necessário à realização dos trabalhos, partindo do pressuposto de que o (a) aluno (a) esteja apto (a) a ingressar formalmente no mercado de trabalho. É premissa fundamental para o desenvolvimento do projeto, que o

Revista ALTERJOR

Grupo de Estudos Alterjor: Jornalismo Popular e Alternativo (ECA-USP)

Ano 10 Volume 02 Edição $22 \quad$ Juho- Dezembro de 2020

Avenida Professor Lúcio Martins Rodrig̉ues, 443, Cidade Universitária, São Paulo, CEP: 05508-020 


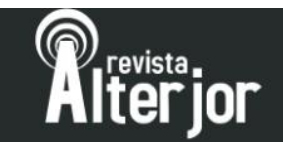

trabalho a ser desenvolvido tenha ou viabilidade comercial (mercadológica) ou relevância cultural.

É interessante observar com a possibilidade advinda do produto jornalístico, que o foco está voltado para lado prático e experimental cujo objetivo é proporcionar ao discente um contato ainda mais próximo com o cotidiano da profissão. Em relação as modalidades de produtos jornalísticos, elas estão categorizadas em nove modalidades como observado abaixo:

\section{Quadro 1}

Modalidades de produtos jornalísticos para o trabalho de conclusão de curso

\begin{tabular}{|c|c|}
\hline Produto Jornalístico & Descrição \\
\hline Livro-reportagem & $\begin{array}{l}\text { Com o objetivo de realizar um livro-reportagem, o } \\
\text { (a) aluno (a) deverá desenvolver um projeto em que } \\
\text { deverá constar a redação final e edição do material no } \\
\text { suporte livro. }\end{array}$ \\
\hline Revista & $\begin{array}{l}\text { Com o objetivo de produzir uma revista, o (a) aluno } \\
\text { (a) deverá desenvolver um projeto (com escolha } \\
\text { definida entre o projeto redacional e o projeto } \\
\text { gráfico) em que deverá constar a captação das } \\
\text { informações a partir das premissas estabelecidas no } \\
\text { item anterior, sem permissão de inserção de } \\
\text { publicidade. }\end{array}$ \\
\hline Jornal & $\begin{array}{l}\text { Com o objetivo de produzir um jornal, o (a) aluno (a) } \\
\text { deverá desenvolver um projeto (com escolha definida } \\
\text { entre o projeto redacional e o projeto gráfico) em que } \\
\text { deverá constar a redação final e edição do material no } \\
\text { suporte jornal. }\end{array}$ \\
\hline $\begin{array}{c}\text { Plano de comunicação de uma assessoria de } \\
\text { comunicação }\end{array}$ & $\begin{array}{l}\text { Com o objetivo de realizar um Plano de } \\
\text { Comunicação, o (a) aluno (a) deverá desenvolver um } \\
\text { projeto em que deverá constar a execução de um } \\
\text { Plano capaz de contemplar os diferentes públicos a } \\
\text { serem atingidos (interno, externo e imprensa), com } \\
\text { estratégias específicas para cada um deles. }\end{array}$ \\
\hline & $\begin{array}{l}\text { Com o objetivo de apresentar um projeto fotográfico, } \\
\text { o (a) aluno (a) deverá desenvolver uma série que } \\
\text { contemple tema de relevância jornalística e (ou) }\end{array}$ \\
\hline
\end{tabular}

Revista ALTERJOR

Grupo de Estudos Alterjor:Jornalismo Popular e Alternativo (ECA-USP)

Ano 10 Volume 02 Edição $22 \quad$ Juho- Dezembro de 2020

Avenida Professor Lúcio Martins Rodrig̉ues, 443, Cidade Universitária, São Paulo, CEP: 05508-020 


\begin{tabular}{|c|c|}
\hline Fotografia (fotojornalismo) & $\begin{array}{l}\text { documental. O produto poderá ser um ensaio ou } \\
\text { fotorreportagem, com proposta apontando para a } \\
\text { relevância do tema escolhido, detendo } \\
\text { aprofundamento no assunto e perspectivas plurais de } \\
\text { investigação. Este trabalho deverá ser acompanhado } \\
\text { de uma apresentação do assunto a ser abordado. A } \\
\text { apresentação final poderá ser uma reportagem } \\
\text { fotográfica ou uma fotodocumentação. }\end{array}$ \\
\hline Documentário televisivo & $\begin{array}{l}\text { Com o objetivo de desenvolver um documentário } \\
\text { televisivo, o (a)aluno (a) deverá desenvolver um } \\
\text { projeto em que conste a captação e edição final do } \\
\text { documentário. O documentário deverá ter um } \\
\text { mínimo de quinze minutos. Pode ser feito por até três } \\
\text { pessoas, sendo a avaliação individual. }\end{array}$ \\
\hline Grande reportagem televisiva & $\begin{array}{l}\text { Consiste numa série de cinco videorreportagens } \\
\text { temáticas, que abordem o mesmo assunto. Ou seja, o } \\
\text { aluno, até o número de quatro, realizará cinco } \\
\text { videorreportagens que constituirão uma série } \\
\text { jornalística televisiva com tempo total de } 15 \text { minutos. } \\
\text { Não há regulação individual de tempo das } \\
\text { videorreportagens. }\end{array}$ \\
\hline Documentário radiofônico & $\begin{array}{l}\text { Com o objetivo de desenvolver um documentário } \\
\text { radiofônico, o (a)aluno (a) deverá desenvolver um } \\
\text { projeto em que conste a captação e edição final do } \\
\text { documentário. O documentário deverá ter um } \\
\text { mínimo de trinta minutos. }\end{array}$ \\
\hline $\begin{array}{l}\text { Produção de um programa em formato radiorevista } \\
\text { ou produto multimídia (webdocumentário) }\end{array}$ & $\begin{array}{l}\text { O aluno (a) deverá desenvolver um projeto que } \\
\text { contemple uma narrativa jornalística numa } \\
\text { perspectiva multimidiática, sendo esta compreendida } \\
\text { como um conjunto convergente dos modos } \\
\text { enunciativos vídeo, áudio, texto, imagem estática e } \\
\text { interatividade, de maneira que a combinação destas } \\
\text { diversas modalidades enunciativas crie uma narrativa } \\
\text { jornalística em suporte hipertextual digital. Dessa } \\
\text { maneira, o (a) aluno (a) poderá desenvolver um } \\
\text { documentário para a web. }\end{array}$ \\
\hline
\end{tabular}

Fonte: Baseado em Universidade Federal do Cariri (2016)

Dentre essas modalidades, três podem ser destacadas em relação ao documento audiovisual: o documentário de TV, a grande reportagem de TV e o webdocumentário. São as três experiências nas quais os discentes podem se aventurar pelo universo da produção audiovisual universitária para a elaboração dos seus TCCs. A partir da 


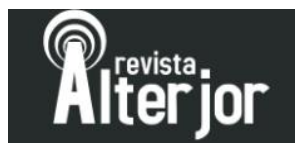

vivência nas disciplinas de Telejornalismo I ( $4^{\circ}$ semestre), II ( $5^{\circ}$ semestre) e do Laboratório de Telejornalismo ${ }^{5}\left(6^{\circ}\right.$ semestre).

\section{Arquivamento, disponibilização e formas de consumo}

Ao discorrer sobre o arquivamento, disponibilização e formas de consumo é importante salientar que o artigo está lidando com a produção audiovisual universitária. Ou seja, com os produtos produzidos pelos próprios discentes no decorrer da graduação. E, com isso, sendo necessária não apenas registrar essas memórias, mas arquivá-las seja para a disponibilização interna, na qual os próprios discentes podem ter acesso e consumir o material já produzido (como forma de consulta, por exemplo); ou exterior, em que os demais sujeitos tanto do curso como da universidade possam acessar e assistir aos materiais audiovisuais que estão sendo desenvolvidos no curso e na região.

A digitalização do audiovisual como explica Saccomori (2016) provoca uma alteração em toda a cadeia audiovisual, desde a produção até o consumo. Ainda de acordo com a autora, essa migração estabelece novos modos de acesso a partir das mudanças estabelecidas do vídeo analógico para o digital. Essa mudança tem sido gradativamente visualizada, principalmente ao observar o cenário do mercado audiovisual com o aumento da produção audiovisual no YouTube, com o IGTV do Instagram e os serviços de streaming audiovisual internacionais como Netflix, Disney +, HBO, Hulu, Amazon Prime entre outros e a Globoplay, como um serviço de streaming nacional que vem ganhando destaque e relevância.

No âmbito acadêmico/universitário a disponibilização dos conteúdos audiovisuais na plataforma digital é uma forma de espalhamento para o acesso e uso, bem como salvaguarda desses documentos. Esse processo pode ser compreendido sob o prisma do diálogo com as novas tecnologias como a convergência tecnológica. Como relata Jenkins (2009), tem-se na contemporaneidade um diálogo entre o meio de comunicação digital e os novos consumidores que estão presentes nesse ambiente

\footnotetext{
${ }^{5} \mathrm{O}$ discente pode optar por realizar alguns dos laboratórios disponíveis na matriz curricular do curso de Jornalismo como, por exemplo, o Laboratório de Impresso, Fotojornalismo, Telejornalismo, Jornalismo Digital ou Assessoria de Imprensa.
} 


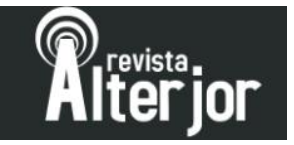

informacional. Assim, tem-se a necessidade do processo de adaptação, das mudanças frente às novas possibilidades estabelecidas pelas transformações.

No caso do curso de Jornalismo da UFCA, o arquivamento tem um grande impacto para a comunidade acadêmica: a) acessar ao que foi produzido; b) estabelecer um diálogo com os outros discentes a partir da visualização das temáticas dos documentários; c) preservação das memórias dos próprios discentes e do curso; e) extrapolar as barreiras de acesso para além da universidade e; e) a criação de práticas de um sistema de memória audiovisual.

De acordo com Souza e Cajazeira (2019: p. 3-4),

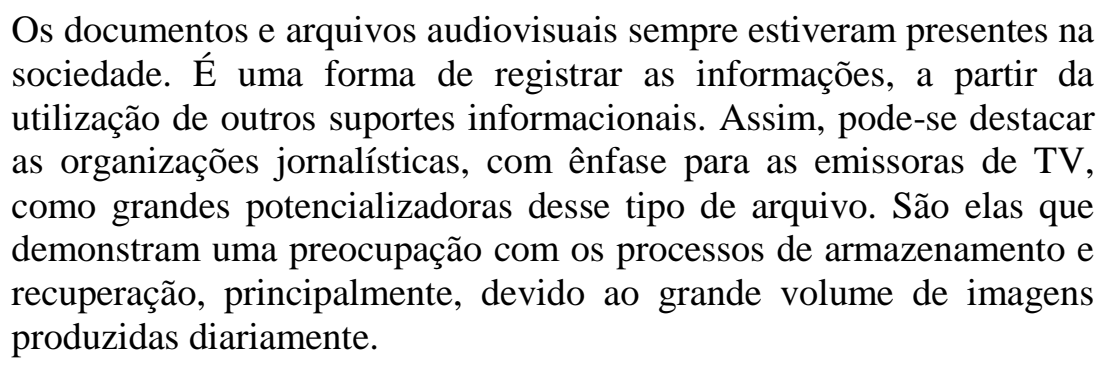

Mas, para além das empresas jornalísticas e emissoras de TV, as universidades, com foco nos cursos de Jornalismo e na produção discente possuem esses arquivos e documentos. Assim, como necessitam da criação de um sistema de arquivamento ou mesmo de uma cultura do arquivamento dessas memórias audiovisuais.

\section{Procedimentos metodológicos}

A pesquisa parte de uma pesquisa exploratória, identificando a realidade do objeto de estudo dentro do espaço acadêmico. Além disso, essa exploração permite destacar as principais dificuldades acerca da relação com o arquivamento e a disponibilização dos documentários no ambiente on-line. O recorte de coleta dos documentários está situado entre os anos de 2013 e 2018, período em que a primeira turma do curso inicia a suas apresentações do TCC até a turma mais que já realizou o depósito dos trabalhos para que os dados possam ser coletados (2018.2).Posteriormente 


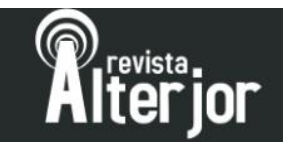

a coleta dos dados, será possível identificar a quantidade de documentários, seus temas e a turmas que produziram esses trabalhos.

\section{Análise e discussão dos resultados}

$\mathrm{Na}$ coleta de dados foram identificados 22 documentários televisivos produzidos pelos discentes, a partir do recorte do período letivo analisado (2013.2-2019.1). A coleta de dados ocorreu tanto na coordenação do curso de Jornalismo sob o uso dos DVDs que continham as informações sobre os documentários, quanto na biblioteca através dos relatórios impressos, que estavam disponíveis para acesso. Somente o produto em si, o documentário, é que não está disponibilizado na biblioteca, visto que ainda não está classificado e indexado.

Ainda na coleta percebe-se a falta de um processo de sistematização e organização desses TCCs audiovisuais, principalmente na coordenação do curso. Uma vez que eles não possuem um check list ou outra forma de controle de entrega desse material. Dessa forma, somente os TCCs mais recentes, com expressividade, (20162019) se encontravam na coordenação. Já os TCCs audiovisuais da primeira turma que apresentou no ano de 2013, apenas estavam disponíveis na biblioteca e somente os relatórios.

\section{Tabela 1}

Documentários produzidos pelos discentes para o Trabalho de Conclusão de Curso de Jornalismo

\begin{tabular}{|c|c|}
\hline Ano & Quantidade \\
\hline 2013 & 2 \\
\hline 2014 & 2 \\
\hline 2015 & 2 \\
\hline 2016 & 2 \\
\hline
\end{tabular}

Revista ALTERJOR

Grupo de Estudos Alterjor: Jornalismo Popular e Alternativo (ECA-USP)

Ano 10 Volume 02 Edição $22 \quad$ Juho- Dezembro de 2020

Avenida Professor Lúcio Martins Rodrig̉ues, 443, Cidade Universitária, São Paulo, CEP: 05508-020 


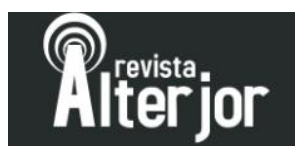

\begin{tabular}{|c|c|}
\hline 2017 & 6 \\
\hline 2018 & 6 \\
\hline 2019 & 2 \\
\hline
\end{tabular}

Fonte: Autor (2019)

Na tabela 1 é possível observar a quantidade de documentários televisivos produzidos pelos discentes. Visualiza-se uma crescente produção e interesse em realizar como TCC um documentário. De 2013 a 2016 o número de documentários de manteve na quantidade, 2 documentários por ano. Mas, nos anos de 2018 e 2019 identifica-se um crescimento exponencial: cerca de $300 \%$ a mais em comparação com os anos anteriores, considerando que apenas o primeiro semestre de 2019 foi inserido na pesquisa. Ou seja, os discentes estão voltando a sua atenção para a produção de produtos audiovisuais jornalísticos para a produção do TCC, como uma das opções de produto jornalístico e monografias.

Esse aumento na elaboração de documentários para o TCC enfatiza a necessidade do arquivamento e disponibilização dos arquivos, seja na versão física ou digital. Acarretando na usabilidade e no consumo dos documentários. Porém, o que se observa é justamente a falta do arquivamento desses produtos audiovisuais, pois ainda que eles estejam na biblioteca ou na coordenação do curso, o seu uso é restrito como no caso dessa pesquisa que obteve ao acesso aos documentos audiovisuais.

Se há um crescimento na produção, pode-se inferir que exista os interesses em poder assistir ao que já foi produzido pelos discentes das turmas anteriores para observar como foram feitos, quais as temáticas tratadas, recorte de imagem, enquadramento, estética entre outros aspectos técnicos de produção e edição do documentário. Porém, esse processo de visualização não pode ser feito já que a disponibilização não ocorre. Assim, essas memórias audiovisuais produzidas pelos discentes caem no esquecimento dentro de uma sala na biblioteca e em uma estante na coordenação do curso. 


\section{Preiejer}

É nesta etapa do arquivamento é onde se encontram as problemáticas, que levaram a realização do artigo e na qual todas as outras etapas sofrem interferências. Como já foi dito, os TCC documentários não estão disponíveis na biblioteca da universidade, pois ainda necessitam passar pelas etapas de classificação e indexação. Estas são etapas fundamentais para a representação da informação e logo, da disponibilização e recuperação da informação. Dessa forma, a sua consulta não pode ser feita pelos usuários seja através do acervo físico ou digital. Como uma cópia também deve ser entregue na coordenação curso, no suporte DVD, lá é possível encontrar esses documentos audiovisuais. Porém, eles também não estão ao menos organizados por data, turma ou qualquer outro tipo de ordem.

Ou seja, visualiza-se a falta de uma cultura do arquivamento ou ainda da relevância necessária a esse tipo de documento audiovisual, desde a biblioteca - que deveria ter esses documentários disponíveis no sistema, visto que os primeiros documentários datam do ano de 2013 - e, também da própria coordenação do curso, como forma de controle e organização dos TCCs dos discentes.

Especificamente no caso com os ambientes digitais de informação é possível identificar alguns possíveis lugares de armazenamento como o site da própria instituição ${ }^{6}$ no qual está contido informações do curso, o site do curso de Jornalismo ${ }^{7}$, o site da disciplina de telejornalismo ${ }^{8}$, o sistema de bibliotecas da UFCA $^{9}$ e as redes sociais digitais como o Facebook ${ }^{10}$ e o YouTube Y $^{11}$.

\footnotetext{
${ }^{6}$ https://www.ufca.edu.br/

${ }^{7} \mathrm{http}: / /$ jornalismo.ufca.edu.br/

${ }^{8} \mathrm{http}: / /$ telejornalismo.ufca.edu.br/

${ }^{9}$ https://catalogo.ufca.edu.br/biblioteca/index.php

${ }^{10} \mathrm{https}: / / \mathrm{www}$. facebook.com/telejornalismoufca/

${ }^{11} \mathrm{https}: / / \mathrm{www}$. youtube.com/user/TVComunicacaoCariri
} 

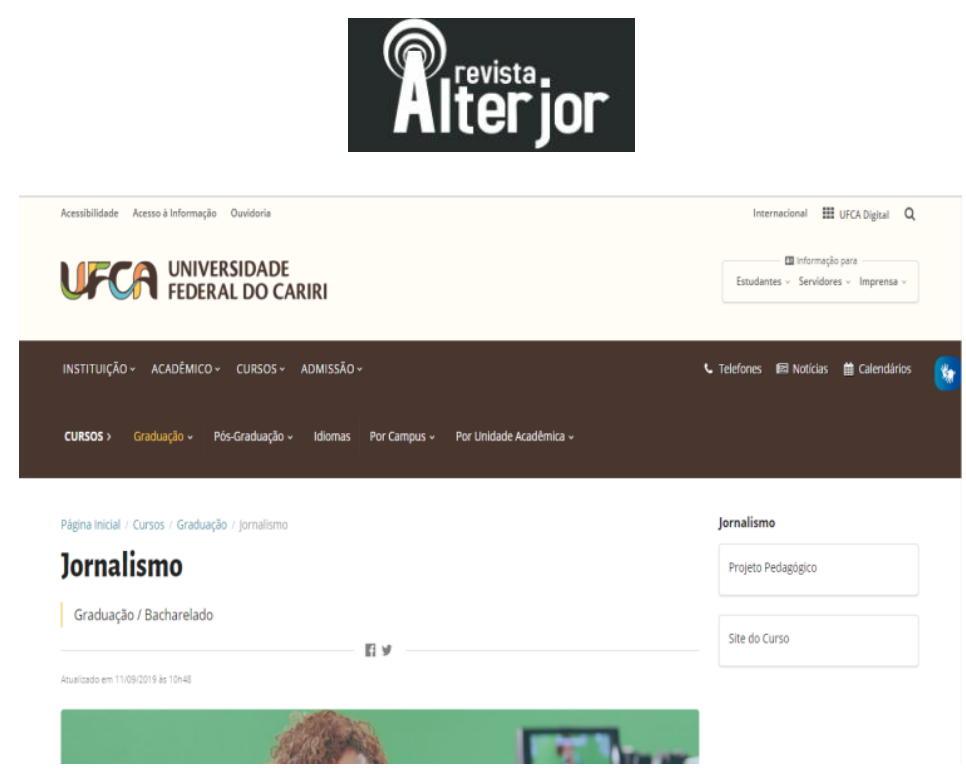

Figura 1: Site da Universidade Federal do Cariri
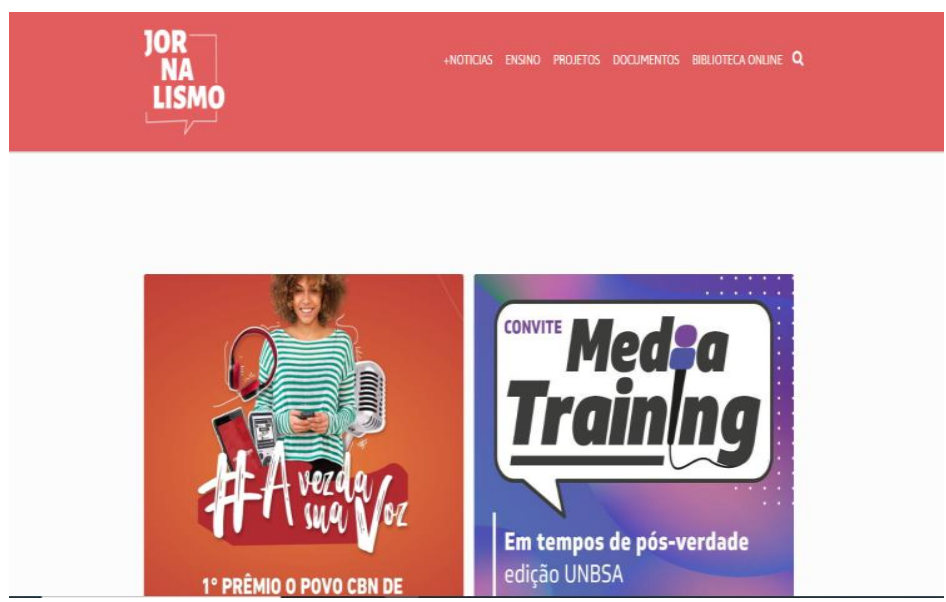

Figura 2: Site do curso de Jornalismo da Universidade Federal do Cariri

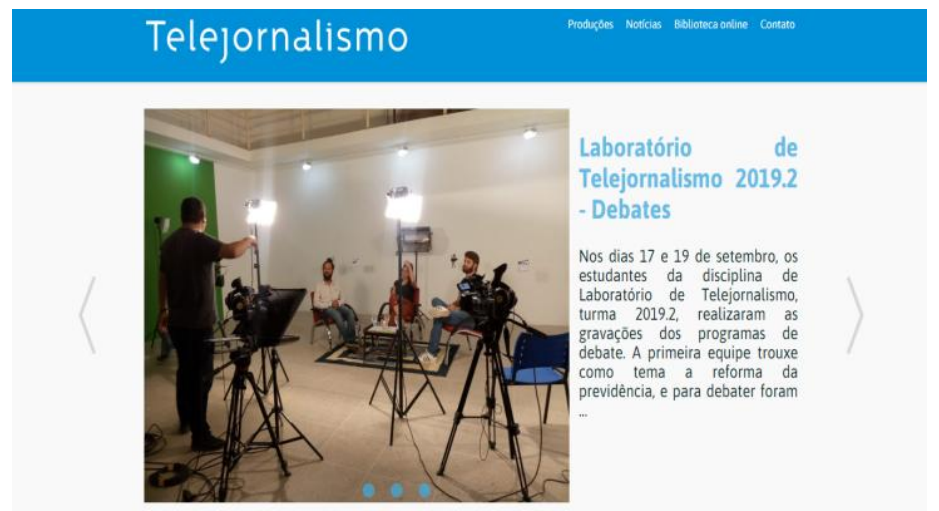

Figura 3: Site do curso da disciplina de Telejornalismo

Revista ALTERJOR

Grupo de Estudos Alterjor:Jornalismo Popular e Alternativo (ECA-USP)

Ano 10 Volume 02 Edição $22 \quad$ Juho- Dezembro de 2020

Avenida Professor Lúcio Martins Rodrig̉ues, 443, Cidade Universitária, São Paulo, CEP: 05508-020 


\section{Anteijor}

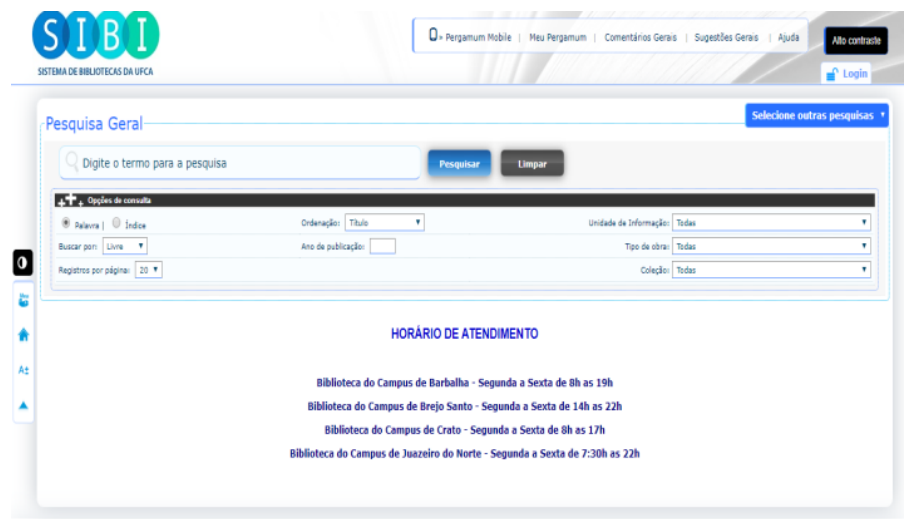

Figura 4: Sistema de Bibliotecas da Universidade Federal do Cariri

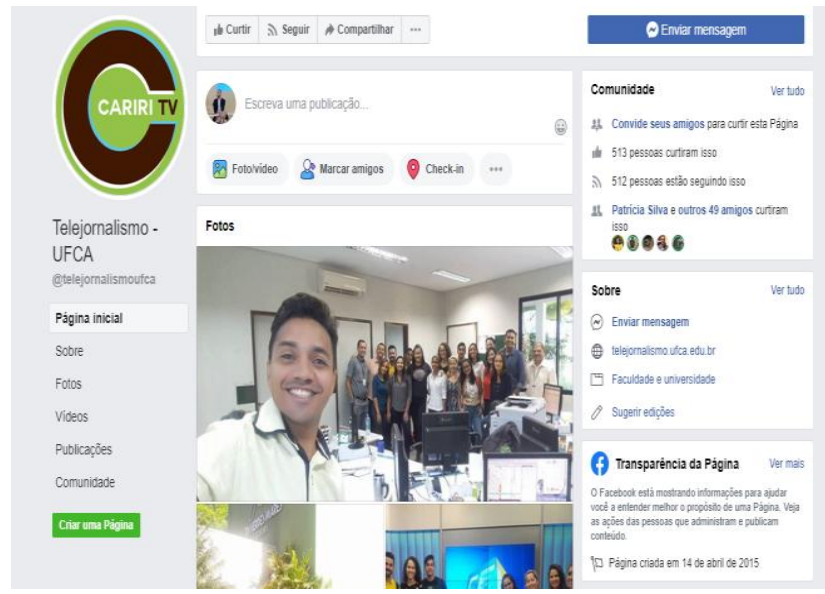

Figura 5: Fanpage da disciplina de Telejornalismo

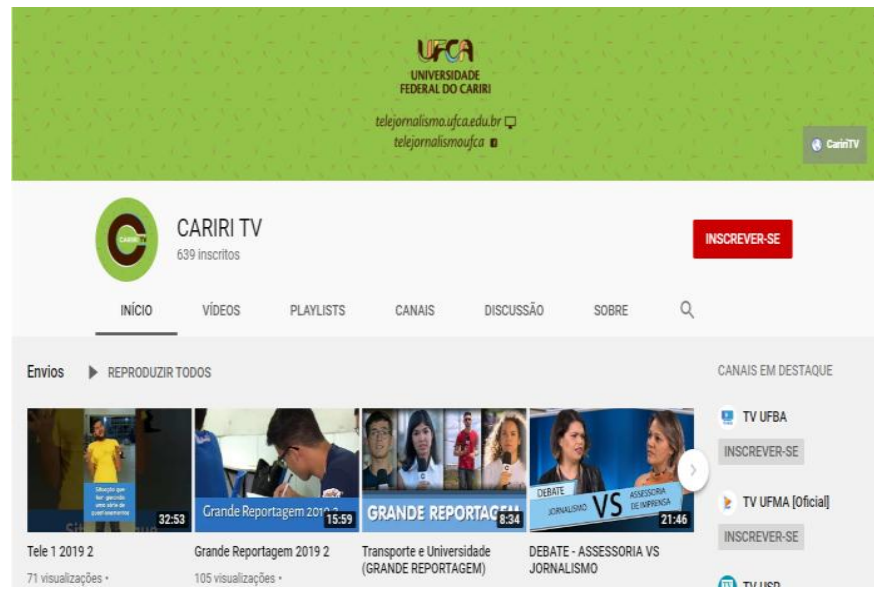

Figura 6: Canal do Youtube da disciplina de Telejornalismo

Revista ALTERJOR

Grupo de Estudos Alterjor:Jornalismo Popular e Alternativo (ECA-USP)

Ano 10 Volume 02 Edição $22 \quad$ Juho- Dezembro de 2020

Avenida Professor Lúcio Martins Rodriģues, 443, Cidade Universitária, São Paulo, CEP: 05508-020 


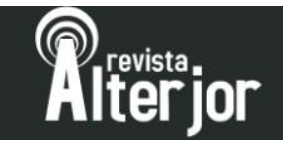

É interessante observar que esses lugares para um possível armazenamento e disponibilização, não estão sendo utilizados para tal finalidade. $\mathrm{O}$ site do curso de Jornalismo, por exemplo, até possui uma aba para a biblioteca on-line, na qual se apresentam um espaço para a inserção dos TCC produtos (documentários) como pode ser observado na figura 7. Porém, na figura 8 identifica-se que eles não estão inseridos nessa biblioteca on-line.
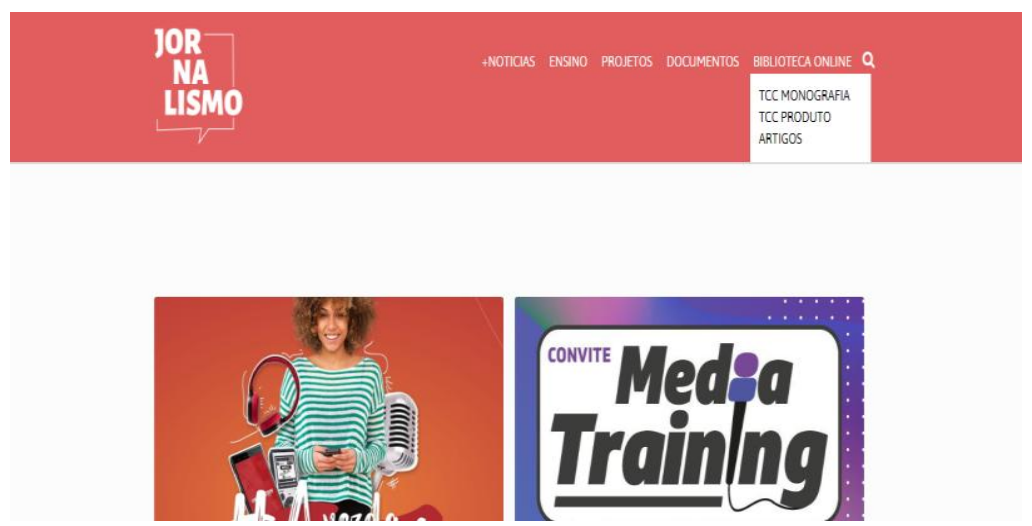

Figura 7: Biblioteca on-line do curso de Jornalismo

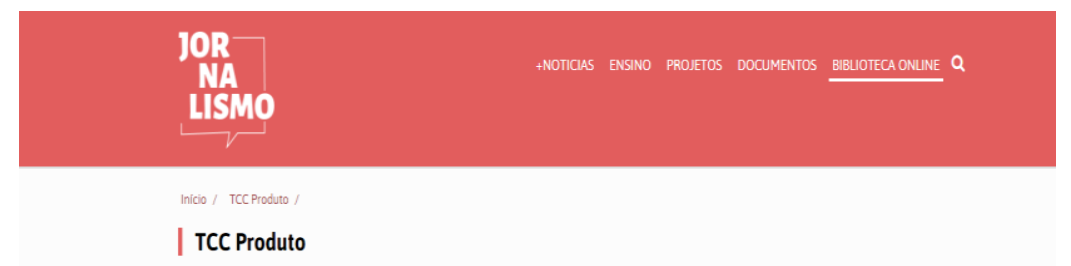

Nầ há postagens para mostrar.

Figura 8: Espaço destinado para os TCCs produtos jornalísticos na biblioteca on-line

Já a fanpage no Facebook do Telejornalismo UFCA, as postagens dos vídeos encontram-se desatualizadas cuja última postagem ocorreu no ano de 2017. Demonstrando que a concentração dos produtos audiovisuais arquivos estão no site da disciplina de telejornalismo e no canal do YouTube. 

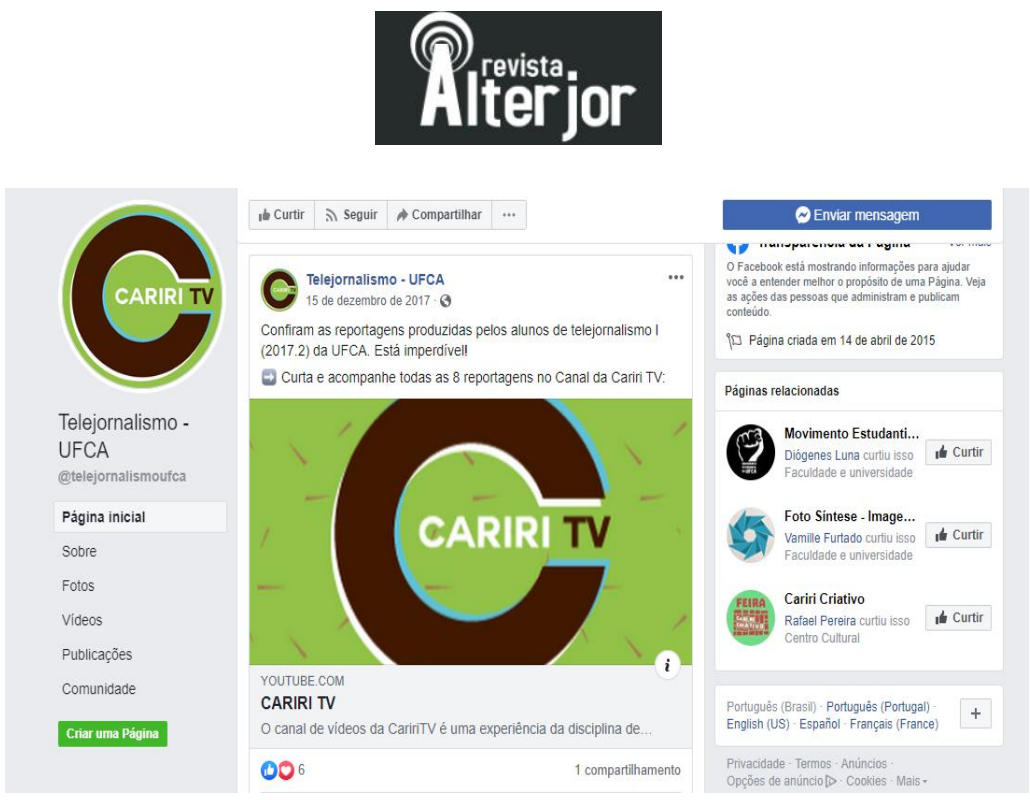

Figura 9: Última postagem de vídeo na fanpage do Telejornalismo UFCA no Facebook

No site da disciplina de telejornalismo é possível encontrar produtos inseridos na plataforma digital como os telejornais, programas de entrevista, debates, reportagens e até mesmo documentários. Esses arquivos e documentos audiovisuais estão dispostos no site na aba "produções", no item "vídeos" (figura 10). Nessas subdivisões o usuário, pode acessar diversas produções realizadas pelos estudantes de turmas diferentes. E, sendo inseridas todas as produções do curso que estão disponíveis no canal do YouTube desde 2012, que antecedem a criação do site no ano de 2015 (figura 11).

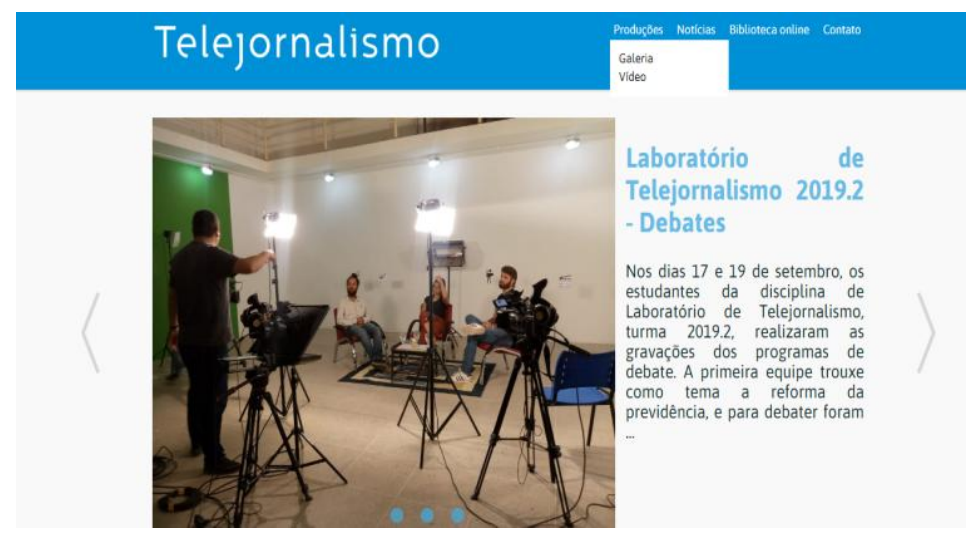

Figura 10: Espaço para o armazenamento das produções da disciplina de telejornalismo on-line 

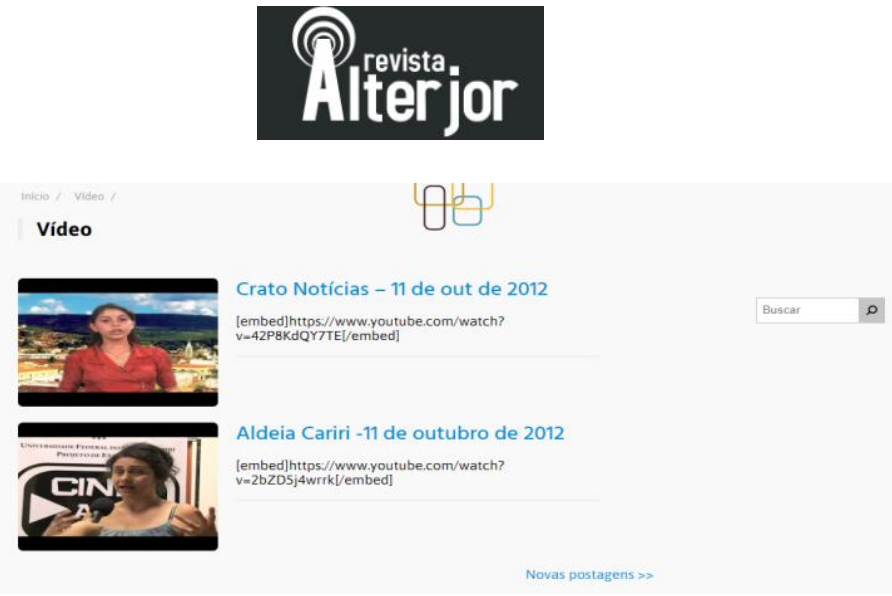

Figura 11: Produtos audiovisuais do canal no YouTube inseridos no site de telejornalismo

Assim, na aba vídeo, o usuário pode encontrar diversas produções de diferentes turmas e formatos de conteúdo audiovisual diferentes. Mas, ao procurar pelos TCCs documentários, verifica-se que não estão nessa plataforma on-line. A prática de arquivamento no site da disciplina foi iniciada em 2015, ano de criação do site. Mas, o canal do YouTube já existia e as demais produções audiovisuais já eram armazenadas lá. O canal denominado Cariri TV, foi criado em 10 de outubro de $2012^{12}$. A primeira produção arquivada data de 11 de outubro de 2012, o programa Aldeia Cariri, produzida pela primeira turma de jornalismo, quando a universidade ainda era a Universidade Federal do Ceará - Campus Cariri (UFC-Cariri) (figura 12).

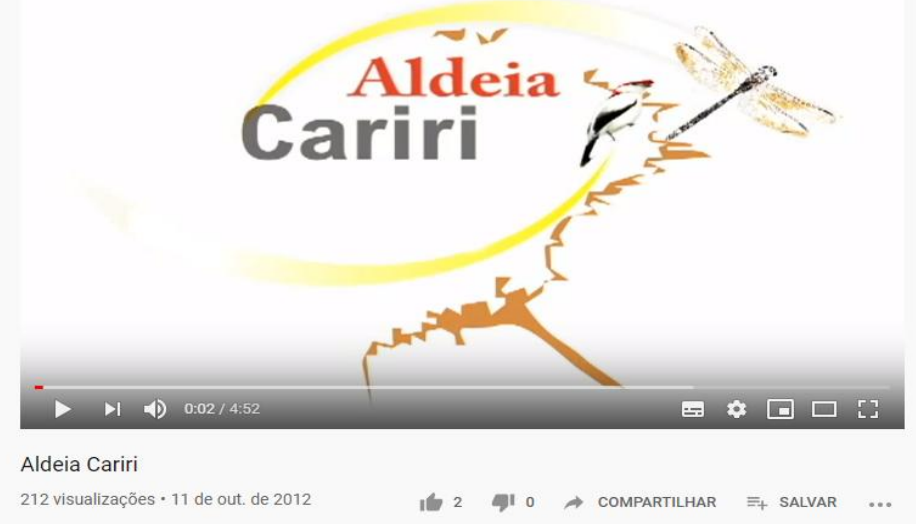

Figura 12: Primeiro documento audiovisual arquivado no YouTube

\footnotetext{
${ }^{12}$ Informação disponibilizada no canal. Em: https://www.youtube.com/user/TVComunicacaoCariri/about 


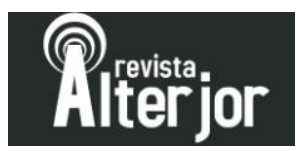

Torna-se fundamental identificar como esses lugares para o armazenamento e acesso ao conteúdo audiovisual possibilitam o intercâmbio acadêmico, a partir da integração e interação entre as turmas, os usuários internos a instituição e exteriores. Além disso, cria-se um sistema de memória audiovisual que possibilita a realização de pesquisas e construção da paisagem audiovisual midiática universitária. O que faz falta são as produções dos TCCs audiovisuais, por possuírem um peso maior, considerando que o discente já passou por todas as disciplinas e poderá apresentar um trabalho final mais elaborado e com um grau de reflexão mais profundo, em comparação com os produtos audiovisuais desenvolvidos nas disciplinas de telejornalismo ao longo da graduação.

\section{Considerações finais}

Diante da realidade exposta do curso de Jornalismo da UFCA, dos TCCs documentários e das práticas de arquivamento que levam a questões como disponibilização, acesso e formas de consumo na sociedade contemporânea, foi possível identificar a ausência dessa prática em determinados produtos audiovisuais. Percebe-se que os produtos elaborados nas disciplinas estão sendo arquivados tanto no site da disciplina quanto no canal do YouTube, mas em relação aos TCCs documentários o mesmo feito não ocorre nos ambientes on-line de informação. Assim, tanto a biblioteca como a coordenação do curso não demonstram uma preocupação com a disseminação desses documentos audiovisuais seja nos ambientes físicos e/ou digital.

É preciso considerar que a demanda de trabalho desses lugares informacionais é grande. Porém, apenas isso não justifica o fato de em 6 anos (2013-2019), desde os primeiros TCCs documentários até os mais recentes, a realidade continue sendo a mesma. Assim, o ambiente universitário, visto como espaço para a reflexão, inovação e desenvolvimento de novas práticas entra em conflito com a falta da disponibilização desses produtos audiovisuais. Produtos que resguardam e revelam a memória da sociedade, do curso e da produção discente jornalística estão guardados em uma sala, em suas caixas sem uma finalidade que demonstre utilidade pública. 


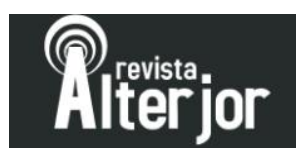

As práticas que já vem acontecendo com os produtos frutos das disciplinas de telejornalismo, servem como exemplos para que até a próprio disciplina venha a disponibilizar esses produtos. E, também o site do próprio curso já que possui um espaço destinado para essa finalidade. Mas, como identificado o que falta é de fato a cultura do arquivamento. Um processo que extrapola as fronteiras do simples arquivar, mas que visa o compartilhamento, a guarda e a memória desses estudantes, dessas memórias audiovisuais da região e das melhorias que tanto o curso quanto a instituição estão acompanhando com o passar do tempo.

\section{Referências bibliográficas}

Alves, Marcia Nogueira; Fontoura, Mara; Antoniutti, Cleide Luciane. (2008). Mídia e produção audiovisual: uma introdução. Curitiba: Ibpex.

Associação dos arquivistas holandeses. (1973). Manual de arranjo e descrição de arquivos. Rio de Janeiro: Arquivo Nacional.

Barbosa, Gustavo Guimarães; Rabaça, Carlos Alberto. (2002). Dicionário de Comunicação. Rio de janeiro: Editora Campus.

Buckland, M. K. Information as thing. (1991). Journal of the American Society for Information Science, v. 42, n. 5, p. 351-360, 1991.

Buckland, M. K. (1997). What is a "document"? Journal of the American Society for Information Science, Medford, v. 48, n. 9, p. 804-809, set.

Cajazeira, Paulo Eduardo; Souza, José Jullian Gomes de. (2019). Acervo audiovisual e virtualização: as potencialidades da tecnologia digital para a preservação da memória. Rizoma, Santa Cruz do Sul, v. 7, n. 1, p. 129, junho. Disponível em: https://online.unisc.br/seer/index.php/rizoma/article/view/12823/8278. Acesso em: 19 ago. 2019.

Cruz Mundet, J. R. (2012). Archivística: gestión de documentos y administración de archivos. Madrid: Alianza Editorial.

Donker-Duyvis, F. (1942). Normalisatie op het gebied der documentatie. The Hauge, Netherlands: NIDER.

Edmondson, Ray. (2017). Arquivística audiovisual: filosofia e princípios. Trad. de Carlos Roberto Rodrigues de Souza. - Brasília: UNESCO.

Edmondson, Ray. (1998). Uma filosofia dos arquivos audiovisuais. Paris: UNESCO.

Jenkins, Henry. (2009). Cultura da convergência. Tradução Susana Alexandria, $2^{\text {a }}$ Ed., São Paulo: Aleph. 


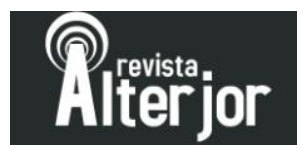

Lee Goff, J. (2003). Documento monumento. In: Le Goff, J. História e memória. Tradução de Irene Ferreira, Bernardo Leitão e Suzana Ferreira Borges. 5. ed. Campinas: UNICAMP.

Otlet, P. (1934). Traité de documentation. Brussels: Editiones Mundaneum, 1934.

Pires, José Miguel Eira. ( 2011). A Importância e Utilidade dos Arquivos Audiovisuais. 62f. Tese (Doutorado) Programa de Pós-Graduação em Ciências da Comunicação, Universidade do Minho, Braga. Disponível em: https://repositorium.sdum.uminho.pt/bitstream/1822/18037/1/Tese\%20de\%20Mestrado. pdf. Acesso em: 29 set. 2019.

Ricoeur, P. (2007). A Memória, a história, o esquecimento. Campinas: Unicamp.

Rossini, Miriam de Souza; Silv, Alexandre Rocha da. (2009). Do audiovisual às audiovisualidades - convergência e dispersão nas mídias. Porto Alegre, RS: Asterisco.

Rossini, Miriam de Souza. (2015). Possibilidades de ubiquidade no audiovisual contemporâneo.In Filho, Washington Souza; Sá, Sônia; Serra, Paulo. A TV ubíqua. Covilhã, Portugal: UBI/ LabCom, Livros LabCom.

Saccomori, Camila. (2016). Práticas de binge-watching na era digital: novas experiências de consumo de seriados em maratonas no Netflix. 246f. Dissertação (mestrado). Programa de Pós-Graduação da Faculdade de Comunicação Social. Pontifícia Universidade Católica do Rio Grande do Sul, Rio Grande do Sul. Disponível em:

http://tede2.pucrs.br/tede2/bitstream/tede/6726/2/DIS_CAMILA_SACCOMORI_COM PLETO.pdf. Acesso em: 9 dez. 2019.

Silva, Eliana. Audiovisual, considerações sobre a imagem e sua leitura. (2011). In: Mandarino, Denis et al. Novas interfaces em comunicação e audiovisual. São Paulo: Lexia.

Smit, Johanna W. (1993). O documento audiovisual ou a proximidade entre as 3 Marias. Texto publicado originalmente na Revista Brasileira de Biblioteconomia $e$ Documentação, $26 \quad$ (1/2): 81-85, jan/jun. Disponível em: http://www.brapci.ufpr.br/documento.php?dd0=0000002163\&dd1=3e67b. Acesso em: 06 jun. 2019.

Souza, José Jullian Gomes de; Cajazeira, Paulo Eduardo Silva Lins. (2019). A memória virtualizada do arquivo audiovisual jornalístico. In: XX Encontro nacional de pesquisa em ciência da informação, 20, Florianópolis. Anais eletrônicos... Santa Catarina: UFSC. Disponível em: https://conferencias.ufsc.br/index.php/enancib/2019/paper/view/474/692. Acesso em: 9 dez. 2019.

Souza, José Jullian G.; Cajazeira; Paulo Eduardo S. Lins. ( 2016). Webdocumentário: a composição narrativa em bases de dados e a interatividade entre o produto audiovisual e o usuário In: XXI Congresso de ciências da comunicação na região sudeste, 21., Salto.

Revista ALTERJOR

Grupo de Estudos Alterjor:Jornalismo Popular e Alternativo (ECA-USP)

Ano 10 Volume 02 Edição $22 \quad$ Juho- Dezembro de 2020

Avenida Professor Lúcio Martins Rodrig̉ues, 443, Cidade Universitária, São Paulo, CEP: 05508-020 
Anais... São Paulo, CEUNSP, 2016. Disponível em: http://www.portalintercom.org.br/anais/sudeste2016/resumos/R53-0443-1.pdf. Acesso em: 27 jul. 2019.

Tauil, Júlio César Silveira; Simionato, Ana Carolina. (2016). O estado da arte da preservação de acervos audiovisuais. XI Seminário de Pesquisa em Ciências Humanas. Disponível em: http://www.proceedings.blucher.com.br/article-details/o-estado-da-arteda-preservao-de-acervos-audiovisuais-23547. Acesso em: 20 jul. 2019.

Universidade Federal do Cariri. (2016). Projeto Pedagógico do Curso de Jornalismo. Juazeiro do Norte: UFCA. Disponível em: https://documentos.ufca.edu.br/wpfolder/wp-content/uploads/2019/08/JornalismoUFCA-Projeto-Pol\%C3\%ADticoPedag\%C3\%B3gico-2016.pdf. Acesso em: 6 dez. 2019.

Vieira, Thiago de Oliveira. (2016). Os documentos audiovisuais, iconográficos e sonoros: uma análise dos atores e suas produções acadêmicas. In: Blanco, Pablo Sotuyo; Siqueira, Marcelo Nogueira de; Vieira, Thiago de Oliveira (Organizadores). Ampliando a discussão em torno de documentos audiovisuais, iconográficos, sonoros e musicais. Salvador: EDUFBA. 